
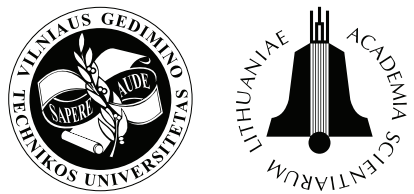

TRANSPORT

2010

25(1): $17-21$

\title{
THE STEEPNESS OF THE RISING BRANCH OF ADHESIVE CHARACTERISTICS BETWEEN WHEEL AND RAIL
}

\author{
Michael Lata ${ }^{1}$, Jaroslav Čáp ${ }^{2}$ \\ The Jan Perner Transport Faculty, University of Pardubice, Studentska 95, \\ 53210 Pardubice, Czech Republic \\ E-mails: ${ }^{1}$ michael.lata@upce.cz; ${ }^{2}$ jaroslav.cap@upce.cz
}

Received 29 April 2009; accepted 1 February 2010

\begin{abstract}
The article describes the limiting parameters of the rising branch of adhesive characteristics. Attention is paid to the actual results of experimental research conducted by the authors. A summary of the obtained knowledge is made. In addition, a test stand of tram wheels driven by the synchronous motor and the carried out experiments are described. A comparison of the achieved results is drawn.
\end{abstract}

Keywords: adhesive coefficient, adhesive characteristics, wheel, rail, relative creep, experimental stand.

\section{Introduction}

Adhesive characteristics (Čáp 1988; Lata 2008; Berthier et al. 2004; Kawamura et al. 2004; Yamazaki et al. 2004; Bureika 2008; Spiryagin et al. 2008) are the property of the mechanism of tangential power transmission between the wheel and the rail and is defined as the dependence of tractive force $T$ or the coefficient of adhesion $\mu$ on relative creep, i.e. $T=f(s)$, resp. $\mu=f(s)$.

In this respect, the rising branch of adhesive characteristics is the most significant factor which at the same time is one of the most important inputs of regulating systems. Such ordering enables the most efficient exploitation of the tractive and braking abilities of the vehicle (Bureika and Mikaliūnas 2008, Dailydka et al. 2008; Spiryagin et al. 2008).

Therefore, it is necessary to determine the value of initial steepness $c_{T s}$, or $c_{\mu s}$ defined as an increment of tractive force, adhesion coefficient, or in relation to a small increment of relative creep.

Theoretical examinations as well as practical research have dealt with this subject for quite some time now, and therefore our participation in this field brings new discoveries. However, before starting, have a brief look back to history.

\section{Evaluation of the Existing Knowledge Regarding the Steepness of the Rising Branch of Adhesive Characteristics}

The first essentially correct solution was introduced by F. W. Carter in the late twenties deriving tangential force intensity between the wheel and the rail from relative creep. In his paper, Carter (1926) defines the following equation:

$$
T=f \cdot s,
$$

where coefficient $f$ includes wheel diameter, the width of the contact surface and standard wheel force. In another paper (Carter 1928), he states that in order to reach the coefficient of adhesion $\mu=0.35$ on the locomotive wheel, relative creep $s=2.86 \cdot 10^{-3} \approx 0.3 \%$ is necessary. When Carter's equation to calculate the maximum steepness of adhesive characteristics ( $r_{1 x}$ - wheel radius; $Q$ - vertical force):

$$
c_{T s \max }=1.46 \cdot 10^{3} \cdot \sqrt{r_{1 x} \cdot Q},
$$

is converted using the formula:

$$
c_{\mu s}=\frac{c_{T s}}{Q},
$$

then the steepness of adhesive characteristics marked as the dependence of the adhesion coefficient on relative creep is defined as:

$$
c_{\mu s \max }=1.46 \cdot 10^{3} \cdot \sqrt{\frac{r_{1 x}}{Q}} .
$$

Kalker's $(1973,1978)$ equation based on the dimensions of the contact surface ( $E$ - Young's modulus; $a$ major semi axes of contact ellipse; $b$ - minor semi axes of contact ellipse):

$$
c_{T s \max }=E \cdot a \cdot b \cdot\left(1.25+0.4 \cdot \frac{a}{b}\right),
$$

converted in the same way will give us the formula for calculating steepness as defined above: 


$$
c_{\mu s \max }=\frac{E \cdot a \cdot b \cdot\left(1.25+0.4 \cdot \frac{a}{b}\right)}{Q} .
$$

Our own research, based on Freibauer's (1983) theory and the relation between the coefficient of friction $\varphi$ and adhesion $\mu$, published earlier, $(\varepsilon$ - gradient of tangential stress in the contact area), where:

$$
\mu=\frac{2}{\pi} \cdot \varphi \cdot\left(\arctan \varepsilon+\frac{\varepsilon}{1+\varepsilon^{2}}\right),
$$

shows that the steepness of adhesive characteristics may be determined directly by means of differentiation:

$$
c_{\mu s}=\frac{d \mu}{d \varepsilon} \cdot \frac{d \varepsilon}{d s} .
$$

The resultant formula then is:

$$
c_{\mu s}=\frac{4}{\pi} \cdot \frac{1}{\rho} \cdot \frac{1}{\left(1+\varepsilon^{2}\right)^{2}} .
$$

Letter $\rho$ stands for the constant of the contact surface to which the following formula applies:

$$
\frac{1}{\rho}=\frac{2 \cdot \pi \cdot a^{2} b \cdot K}{3 \cdot Q} .
$$

The parameter discussed in formula (9) reaches its highest value when $\varepsilon=0$, i.e.:

$$
c_{\mu s \max }=\frac{4}{\pi} \cdot \frac{1}{\rho} \text {. }
$$

Hence, our discovery shows that the effective branch of adhesive characteristics reaches its maximum steepness at the initial stage and that this steepness is independent of the coefficient of friction $\varphi$. Apart from $4 / \pi$, it depends only on the constant of the contact surface $\rho$, see (10).

If a substitution for it is made in equation (11), we get:

$$
c_{\mu s \max }=\frac{8}{3} \cdot \frac{a^{2} \cdot b \cdot K}{Q},
$$

which is also an alternate expression of Kalker's (1973, 1978 ) coefficient $c_{11}$, though in addition, it includes the elasticity constant of touching object materials $(K)$ the value of which has experimentally been found to be $K=$ $2.5 \cdot 10^{10} \mathrm{kN} \cdot \mathrm{m}^{-3}$.

The original Kalker's $(1973,1978)$ coefficient was based on his theory of elastic deformations published by Fiehn et al. (1979). However, its practical application at Knorr-Bremse Company failed. Saumweber and Winkle (1981) state that 'adhesive characteristics based on the assumption of elastic deformations are not applicable for the braking mode'.

Numerous experiments have shown that the steepness of the rising branch is, in fact, significantly smaller than that suggested by this theory. In his paper, Kalker (1978) responded that the slip and elasticity of touching objects were influenced by the actual condition of the object surfaces. This claim was based on the experiments conducted by Johnson (1958). According to their findings, the deformations of the wheel and the rail do remain elastic; however, their surfaces, though are never ideal, have an influence on the actual size of creep which means that characteristic steepness is, in fact, smaller in comparison with the previous theories.

Now, let us have a look at some typical combinations of wheel radius $r_{1 x}$ and vertical force $Q$.

The numerical values of steepness will be calculated using (4), (6) and (12) and then compared to the results of the conducted experiments.

In addition, the relative creep size is provided corresponding to the chosen value of the adhesion coefficient ( $\mu=0.3$ in this case) which serves as a comparative parameter.

$$
\begin{array}{lll}
r_{1 x}=0.5 \mathrm{~m} ; Q=100 \mathrm{kN}: & \\
(4): & c_{\mu s}=1.03 \cdot 10^{2} & \left(s_{(0.3)}=0.0029\right) ; \\
(6): & c_{\mu s}=1.55 \cdot 10^{2} & (s=0.0019) ; \\
(12): & c_{\mu s}=1.66 \cdot 10^{2} & (s=0.0018) ; \\
(11): & c_{\mu s}=1.64 \cdot 10^{2} & (s=0.0018)
\end{array}
$$

$r_{1 x}=0.625 \mathrm{~m} ; Q=105 \mathrm{kN}$ :

$$
\begin{array}{rll}
(4): & c_{\mu s}=1.13 \cdot 10^{2} & (s=0.0024) ; \\
(6): & c_{\mu s}=1.66 \cdot 10^{2} & (s=0.0018) ; \\
(12): & c_{\mu s}=1.88 \cdot 10^{2} & (s=0.0015) ; \\
(11): & c_{\mu s}=1.88 \cdot 10^{2} & (s=0.0016) .
\end{array}
$$

In both cases, the presented results may be compared to the values obtained through experiments conducted by Cejka (1968) and Fiehn et al. (1979).

$$
c_{\mu s}=1.50 \div 2.0 \cdot 10^{2} \quad(s=0.0015 \div 0.0017) .
$$

Those measurements took place in the late sixties. Later, similar measurements were carried out by Fiehn et al. (1979) but this time on vehicles driven by asynchronous motors. The results were as follows:

$$
\begin{aligned}
& c_{\mu s}=1.20 \cdot 10^{2} \quad(s=0.0025) \text { dry rails, } V=47 \mathrm{~km} / \mathrm{h} ; \\
& c_{\mu s}=0.54 \cdot 10^{2} \quad(s=0.0055) \text { wet rails, } V=90 \mathrm{~km} / \mathrm{h} .
\end{aligned}
$$

Steepness ranges for typical surface conditions:

$$
\begin{aligned}
& c_{\mu s}=1.60 \div 1.40 \cdot 10^{2} \quad(s=0.0018 \div 0.0021) \text { dry; } \\
& c_{\mu s}=0.90 \div 0.55 \cdot 10^{2} \quad(s=0.0033 \div 0.0054) \text { wet; } \\
& c_{\mu s}=1.00 \div 0.90 \cdot 10^{2} \quad(s=0.0030 \div 0.0033) \text { wet, sanding. }
\end{aligned}
$$

Frederich (1970) carried out extensive experiments on tram vehicles; his article provides valuable information on drawing a comparison. First, let us present the calculated theoretical values of tram wheels:

$$
\begin{array}{lll}
r_{1 x}=0.36 \mathrm{~m} ; Q=30 \mathrm{kN}: & \\
(4): & c_{\mu s}=1.60 \cdot 10^{2} & (s=0.0018) ; \\
(6): & c_{\mu s}=1.90 \cdot 10^{2} & (s=0.0015) ; \\
(12): & c_{\mu s}=1.20 \cdot 10^{2} & (s=0.0025) ; \\
(11): & c_{\mu s}=1.17 \cdot 10^{2} & (s=0.0025) .
\end{array}
$$

In Frederich's (1970) article, theoretical values are calculated using equation (12).

The measurements carried out on a specially modified tram powered by the vehicle of $600 \mathrm{~V} \mathrm{DC}$ and DC serial motors are of a considerable significance. From the 
tables published, steepness $c \mu$ s can be determined in the range of $c_{\mu s}=(0.6-1.0) \cdot 10^{2}$ for $s=(0.0030-0.0050)$ while the maximum value may be $c_{\mu s}=1.2 \cdot 10^{2}$ for $s=0.0025$.

We share the same area of interest applying to the tram wheel driven by a synchronous motor.

\section{Our Experiments Conducted on the Test Stand}

At the Jan Perner Transportation Faculty of the University of Pardubice, experimental research was conducted in the field of driving dynamics and adhesion. A special test stand consisting of a rotating rail rig and a tram wheel driven by a synchronous motor was constructed. This project was originally carried out by the company VUKV a.s. (Research, Development and Testing of Railway Vehicles). Later, the stand underwent an extensive reconstruction of its mechanical and electrical parts, including (Fig. 1):

1) a supporting frame with a handling platform;

2) a pneumatic control system of vertical thrust generation;

3) driven wheel with a propeller shaft;

4) synchronous traction motor;

5) rotating rail;

6) asynchronous brake motor.

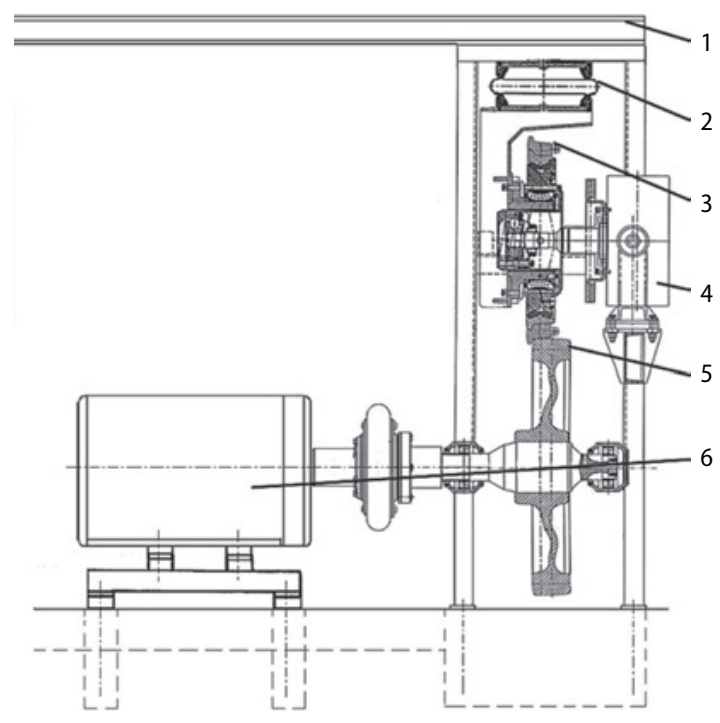

Fig. 1. The main parts of the test stand

The angular velocities of the tram wheel and rotating rail rig are scanned using highly sensitive rotary sensors. There are 4000 impulses per revolution in the wheel sensor and 1024 of those in the rail sensor. The hardware and software of the test stand work with the time interval of $64 \mathrm{~ms}$ which only allows for lower accuracy.

Currently, the wiring and operating system are complete. In this area, we work together with the specialists from the Department of Electrical Engineering, Electronics and Traffic Safety Technologies as operating a synchronous motor is no simple matter.

By the end of the year 2008, two types of experiments had been conducted on the test stand. First, the simulations of exceeding the limits of adhesion with varying input parameters of velocity were carried out and the conditions of contact surfaces were established; second, the processes of transition from braking to traction and vice versa took place under varying conditions.

At the start of each experiment, breaking torque (loading motor torque) was set to the value (approximated from the vertical thrust and creep), where the coefficient of adhesion corresponded to the normal tractive mode. Then, torque was gradually increased until it reached the limit of adhesion where a significant creep rise was observed.

The simulation of reaching the limits of adhesion was conducted at varying speeds on dry contact surfaces which consequently were degreased with benzine and the limits of adhesion were tested again at the same speeds as before.

On the contrary, in the second set of the carried out experiments, i.e. the simulation of transition between the tractive and braking modes reaching adhesion limits in either mode was undesirable.

The main attention was given to the course on adhesive characteristics around the point zero in transition between the opposite quadrants of complete adhesive characteristics. The variables were the same as for the simulation of reaching the limits of adhesion, i.e. the velocity and condition of contact surfaces. To verify the existence of $\mathrm{B}-\mathrm{H}$ loops in adhesion characteristics, its course being monitored in both directions during each test. The thrust of $400 \mathrm{kN}$ was applied in all cases while speeds were $15,26,40$, and $60 \mathrm{~km} / \mathrm{h}$.

\section{Evaluation of Results}

First, let us have a look at the recorded readings. The first set of readings shows the limit values of adhesion between contact surfaces. At the velocity of $15 \mathrm{~km} / \mathrm{h}$, the coefficient of adhesion $\mu=0.2$ was reached. In the following experiments, this value reached 0.3 as a result of an increased coefficient of friction after contact surfaces had been cleansed.

Another experiment reveals that a greasy layer was applied for both wheels and measurements and taken at the speeds of 40 and $60 \mathrm{~km} / \mathrm{h}$. The coefficient of adhesion was significantly smaller this time and nearly the same for both speeds, i.e. $\mu=0.12-0.14$. Considering such surfaces, these values may probably be considered to be the minimum (Fig. 2).

Before the following experiments were performed, contact surfaces had been thoroughly degreased with benzine. At the speed of $15 \mathrm{~km} / \mathrm{h}$, the peak value of the previously recorded adhesive characteristics was gradually rising up to the highest coefficient of adhesion reached with the value lower than 0.4 .

The further rising of the previously reached limit of adhesion has been explained by the authors to be due to the fact that with each slip of the wheel, contact surfaces are a little cleaner. At the speeds of $40-60 \mathrm{~km} / \mathrm{h}$, the limit value of adhesion was found to be $\mu=0.44-0.48$ (Fig. 3). 


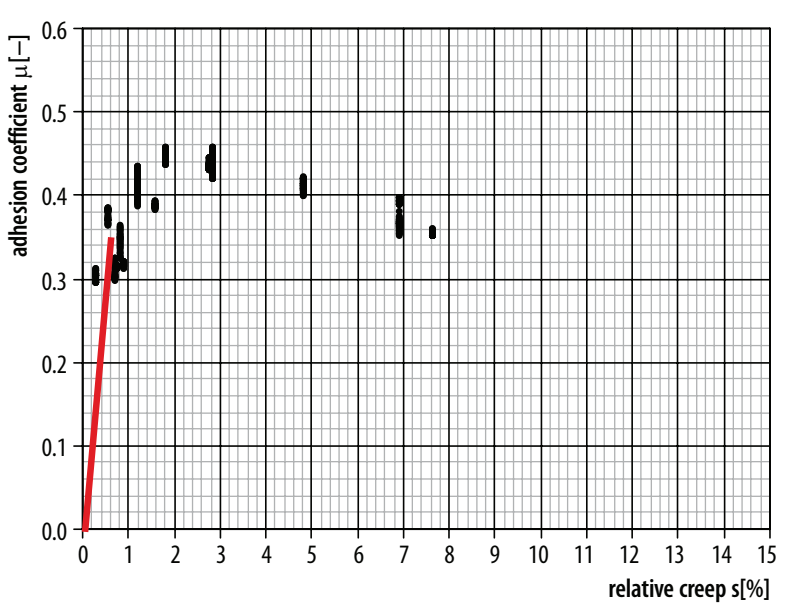

Fig. 2. The linear approximation of the rising branch of adhesive characteristics (at the speed of $40 \mathrm{~km} / \mathrm{h}$ on a slippery surface)

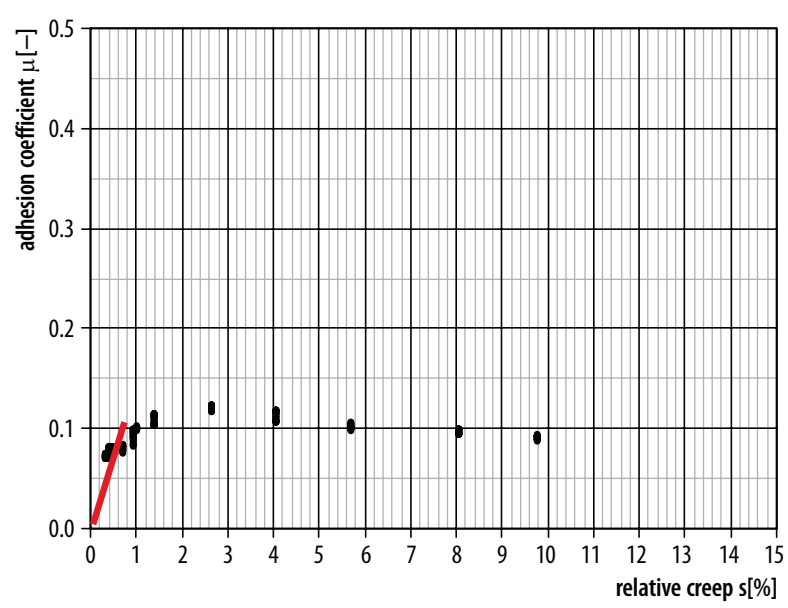

Fig. 3. The linear approximation of the rising branch of adhesive characteristics (at the speed of $40 \mathrm{~km} / \mathrm{h}$ on a dry surface)

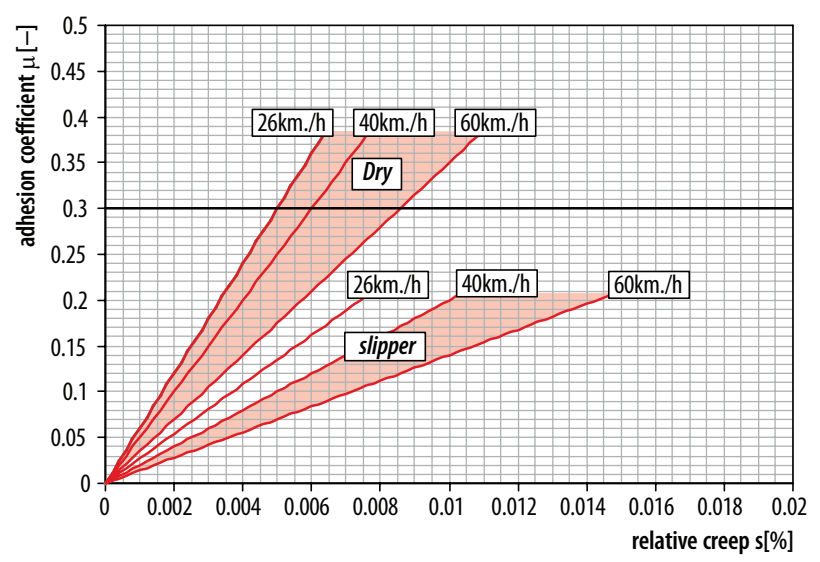

Fig. 4. Ranges of steepness under different conditions

Now, let us have a look at the analysis of the rising branch of adhesive characteristics. The rising branch has been approximated by a linear function. Fig. 4 shows the ranges of the slopes of its lines for different velocities and contact surface conditions. The measured values of steepness are as follows:

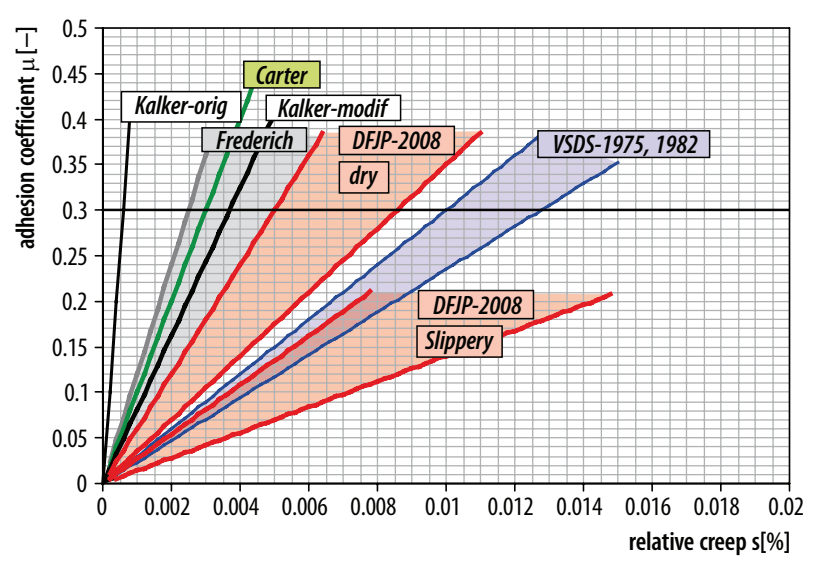

Fig. 5. The measured values of steepness compared to other authors

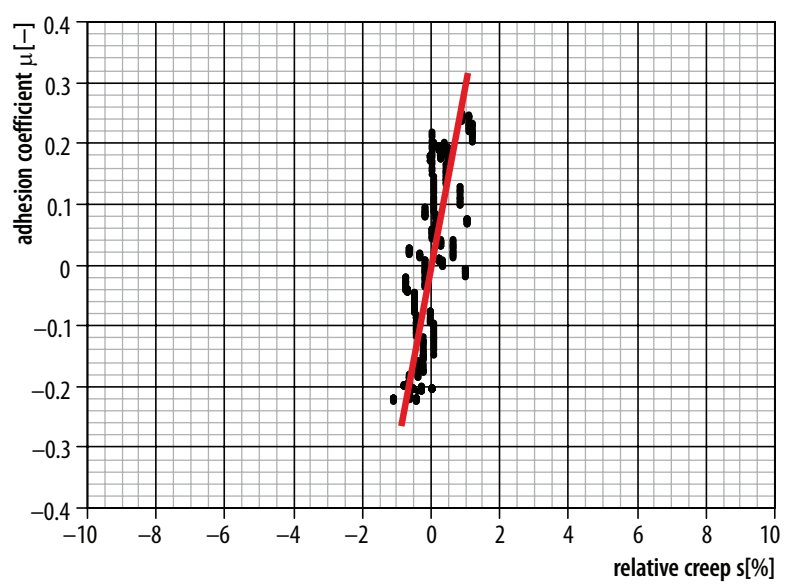

Fig. 6. Transition from traction to the braking mode (on dry surface)

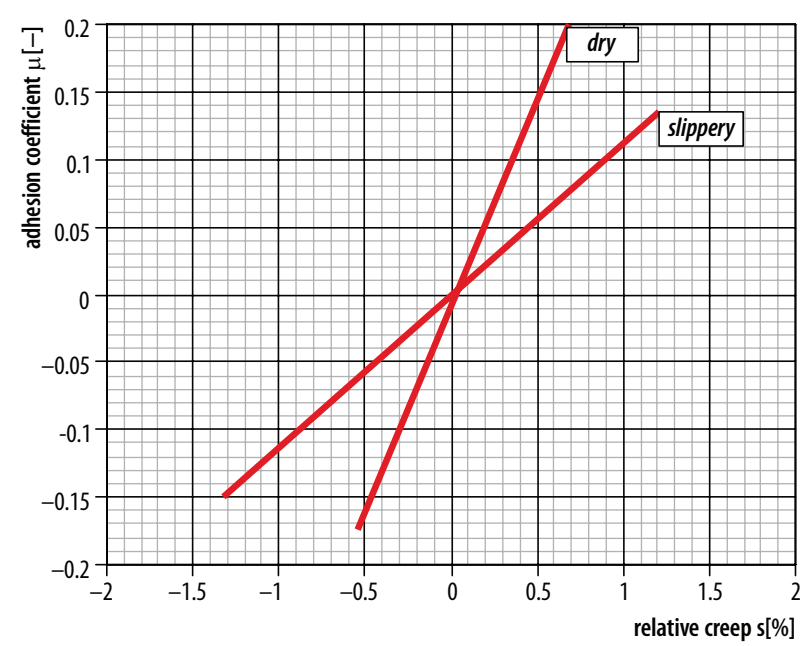

Fig. 7. Steepness of transition for dry and slippery surface

$c_{\mu s}=0.14 \cdot 10^{2} \div 0.27 \cdot 10^{2}$, slippery surface; $c_{\mu s}=0.35 \cdot 10^{2} \div 0.60 \cdot 10^{2}$, dry surface.

In Fig. 5, the above ranges are compared to the results of the experiments undertaken by Čáp (1988) in 1975-1982 at the University of Žilina and to the findings of the other authors. 
The results of the experimental simulation of transition between the tractive and braking modes were also used to determine the steepness of the rising branch of adhesive characteristics (Fig. 6). In the region of very small slips $(0.5 \%)$, the following values of the slope of linear dependency have been derived (Fig. 7):

$$
\begin{aligned}
& c_{\mu s}=0.14 .10^{2}, \text { slippery surface; } \\
& c_{\mu s}=0.35 .10^{2}, \text { dry surface. }
\end{aligned}
$$

\section{Conclusion}

Two sets of experiments have been conducted on the tram wheel test stand. The first one was designed to determine the highest coefficient of adhesion reached recording complete adhesive characteristics. The second set of experiments observed transition between traction and braking modes. In rising branches, the gradient was determined which is important for anti-slip regulation devices. Research will be continued. The reconstruction of the mounting mechanism of the rotating rail rig is currently taking place which will allow to set it at different angles and observe the deformation of adhesive characteristics at non-zero rising angles.

\section{Acknowledgement}

This article was written with the support of VCKV (Research Centre of the Railway Vehicles) and financed through the project financing of MSMT (the Ministry of Education, Youth and Sports of the Czech Republic), Registration Number: MSMT 1M0519.

\section{References}

Berthier, Y.; Descartes, S.; Busquet, M.; Niccolini, E.; Desrayaud, C.; Baillet, L.; Baietto-Dubourg, M. C. 2004. The role and effects of the third body in the wheel-rail interaction, Fatigue \& Fracture of Engineering Materials \& Structures 27(5): 423-436. doi:10.1111/j.1460-2695.2004.00764.x

Bureika, G. 2008. A mathematical model of train continuous motion uphill, Transport 23(2): 135-137. doi:10.3846/1648-4142.2008.23.135-137

Bureika, G.; Mikaliūnas, Š. 2008. Research on the compatibility of the calculation methods of rolling-stock brakes, Transport 23(4): 351-355. doi:10.3846/1648-4142.2008.23.351-355

Carter, F. W. 1926. On the action of a locomotive driving wheel, Proceedings of the Royal Society of London. Series A, Containing Papers of a Mathematical and Physical Character 112(760): 151-157.

Carter, F. W. 1928. On the stability of running of locomotives, Proceedings of the Royal Society of London. Series A, Containing Papers of a Mathematical and Physical Character 121(788): 585-611.

Čáp, J. 1988. Strmost vzestupné větve adhezní charakteristiky [Slope of the increasing branch of the adhesive characteristics], Železniční technika [Railway Technique] 1(88): 12-16.

Čejka, J. 1968. Adhesní vlastnosti elektrických lokomotiv na střídavý proud [Adhesive properties of AC electric locomotives]. Technický zpravodaj Škoda Plzeň [Technical Report of Skoda Plzen].

Dailydka, S.; Lingaitis, L. P.; Myamlin, S.; Prichodko, V. 2008. Modelling the interaction between railway wheel and rail, Transport 23(3): 236-239.

doi:10.3846/1648-4142.2008.23.236-239
Fiehn, H.; Weinhardt, M.; Zeevenhooven, N. 1979. Drehstromversuchsfahrzeug der Niederländichen Eisenbahnen - Adhässions - messungen [Phase current of the test vehicle Nederland railways - Adhesions - Measurements], Elektrische Bahnen [Electric Railways] 12: 329-338.

Frederich, F. 1970. Kraftschlussbeanspruchtung am schrägrollenden Schienenfahrzeug-rad [Adhesion at oblique rolling railway wheel], ZEV DET 94(2/3): 96-94.

Freibauer, L. 1983. Adheze kola na vozidlové dráze [The adhesion of wheel on track], in Proceedings of the 7th Scientific Conference of the College of Transport and Communications in Žilina, 214-219.

Johnson, K. L. 1958. The effect of a tangential contact force upon the rolling motion of an elastic sphere upon a plane, Journal Applied Mechanics 25: 339-346.

Kalker, J. J. 1973. Simplified theory of rolling contact, Delft Progress Rep. Ser. C1: 1-10.

Kalker, J. J. 1978. Über die Mechanik Kontaktes zwischen Rad und Schiene [About the contact mechanics between wheel and rail], ZEV DET 102(7/8): 214-218.

Kawamura, A.; Takeuchi, K.; Furuya, T.; Cao, M. F.; Takaoka, Y.; Yoshimoto, K. 2004. Measurement of tractive force and the new maximum tractive force control by the newly developed tractive force measurement equipment, Electrical Engineering in Japan 149(2): 49-59. doi:10.1002/eej.10376

Lata, M. 2008. The modern wheelset drive system and possibilities of modelling the torsion dynamics, Transport 23(2): 172-181. doi:10.3846/1648-4142.2008.23.172-181

Saumweber, E.; Winkle, G. 1981. Eine neue Generation für die Eisenbahn unter Verwendung vor Mikroprozessoren [A new generation for the railroad before using microprocessors], Elektrische Bahnen [Electric Railways] H.9: 331-336.

Spiryagin, M.; Lee, K. S.; Yoo, H. H. 2008.Control system for maximum use of adhesive forces of a railway vehicle in a tractive mode, Mechanical Systems and Signal Processing 22(3): 709-720. doi:10.1016/j.ymssp.2007.09.018

Yamazaki, H.; Nagai, M.; Kamada, T. 2004. A study of adhesion force model for wheel slip prevention control, JSME International Journal Series C-Mechanical Systems Machine Elements and Manufacturing 47(2): 496-501. doi:10.1299/jsmec.47.496 